\title{
Integrated Functional Adult Literacy: Existing Practices and Challenges in Eastern Ethiopia
}

\author{
Sisay Awgichew*, Yilfashewa Seyoum
}

Department of Adult Education and Community Development, College of Education and Behavioural Sciences, Haramaya University, Ethiopia

Corresponding author: Sisay Awgichew, E-mail: Sisay0171@gmail.com

\section{ARTICLE INFO \\ Article history \\ Received: June 06, 2017 \\ Accepted: October 26, 2017 \\ Published: October 31, 2017 \\ Volume: 5 Issue: 4 \\ Conflicts of interest: None \\ Funding: Haramaya University \\ Notice: The reseracher used \\ Integrated Functional Adult \\ Literacy and Integrated Functional \\ Adult Education interchangeably. \\ Acknowledgement \\ We would like to Acknowledge Haramaya University the office of research affairs for its financial support to accomplish this study.}

\begin{abstract}
The purpose of this study was to examine the existing practices and challenges of Integrated Functional Adult Literacy Program in eastern Ethiopia. To achieve this objective, the researchers used mixed research design. Questionnaires, interview and focus group discussions were used as viable instrument for data collection. The questionnaires were filed by 302 adult learners and 153 facilitators. Data were analyzed using descriptive statistics. The findings revealed that since the introduction of adult education programs with an integrated manner, harmful traditional practices are reduced, community participation in environmental conservation are growing; societal life skills and usage of new agricultural technologies are improved. However, dysfunctional management structure, poor institutionalization, integration and coordination among the sectors, lack of financial package, trained personnel and low and inconsistent salary were the major bottlenecks in the implementation of the program. Therefore, collaborative efforts among government, NGOs and the community need to put in place to alleviate both human and non-human related problems for the effective realization of the program with pioneering structure, financing,organization and management to achieve transformational and sustainable development goals.
\end{abstract}

Keywords: Integrated, Functional, Adult, Adult Education, Eastern Ethiopia

\section{INTRODUCTION}

Education is an indispensable tool for multidimensional development: social, economic, political and cultural aspects (MoE, 2008). It is mainly concerned with liberation of man from ignorance and poverty. It plays an imperative function in the transformation and improvement of society (Ghash \& Zachriah, 1987). In the continuous conferences, different bodies of the United Nations, the issues of Education for All (EFA), environment, human right, population, social development, women empowerment, human settlement and food security addressed since 1990s. These series of conferences recognized that transformation would be dependent on adult member of the society, transforming their life situations and gaining greater control of their lives. To attain these changes, adults necessitate latest knowledge, skills and attitudes (Sabo \&Mapofu, 2006). Adults, the immediate producers in the society, need to keep on learning throughout lifespan in lifelong learning (LLL) and life-wide education so as to catch up with rapid changes in the society and en-sure sustainable development (Galabawa 2005, as cited in Blackson, 2008).

Adult education usually refers to any form of learning undertaken by or provided for mature men and women outside the formal system (Seya, 2014). It targets girls and boys above 15 years of age as well as those who are poor and underprivileged. Adult education contents mayincludeincome generation, health, literacy, numeracy, knowledge, life skills and problem solving. It is considering as a remedying early education and self-fulfilment. These geared the society towards active involvement in economic, social and political life (Seya, 2014). The importance of adult education is growing in the third world, for many see it as a valuable instrument for sustainable development (Nafukho, 2011). It has been considering as a bridge between the desires of some to achieve a higher income and social statues on the one hand and the development goal of the government on the other hand (Rogers, 1992). Adult education consists of systematic and organized educational activities to deal with any area of life, including family, work, and health matters (Coombs, 1985 as cited Jossey-Bass, 2007).

The various ESDP documents in Ethiopia have clearly shown that among the different options in the system of Non-formal Education (NFE), Integrated Functional Adult Literacy Programs (IFALP) found as the most pertinent one in Ethiopian contexts. The concept of IFALP was developed in 1960s and implemented in several countries onward 1970s (Bohla, 1995 cited in Dabal H, 2011). Besides, Functional Adult Literacy Program (FALP) was initiated at the world conference of MoE on the eradication of illiteracy on Teheran, Iran in September 1965. Director General of UNESCO (Bohla, 
1994 as cited in Tekalign, 2010) brought in merging FAL program to educational progress as a whole to focuses. Functional Adult Literacy (work oriented Literacy) is at infant stage in the third world. Its newest manifestation may be literacy integrated with income generation. Bhola (1984) stresses that proper and organized IFALP has advantages for individual to be independent in his/her daily activity as it helps the individual to increase productivities, to improve his/her status in the societies and to assist him/her in upward mobility in the social structure. The government of Ethiopia attempted to mobilize the scarce resources and develop the partnerships essential to sustain Adult Education Program as stipulated in the Education Sector Development Program (ESDP V2015/2016 -2019/2020). Recently, the government of Ethiopia has been working to address more than 19 million illiterates across the country. However, the practices and challenges are not yet investigated in-depth. Therefore, it is rational to inquire whether such practices and interventions have a momentous impact on the road to middle lower income country by 2025 . To understand the situation and develop a general platform for the implementation of IFAEP, the researchers considered the current topic in order to examine the existing practices and challenges of IFALP in Eastern Ethiopia.

\subsection{Statement of the Problem}

In Ethiopia, education is at the centre of the government policy targeted at achieving middle-income country status in the next decades (ESDP IV 2009/10-2014/15). The education sector both formal and non-formal should provide capable citizens with core literacy and numeracy skills and with the middle and higher-level capacities needed by the emerging productive sectors. Ethiopian Federal Ministry of Education recognised that increasing adult literacy rates would support other development goals (MoE, 2006). Mothers education is directly or indirectly associated with infant mortality, child health and schooling (MoE, 2006).

During the 1960s, adult learning has taken to be a key component of most strategies for development. In this day's rapid changing societies, adult education is a branch of the lifelong education endeavour through which community keep up with changing development (MoE, 2006). Taking this policy in to consideration, the new national adult and alternative basic education strategies of Ethiopia initiate for the formation of adult non-formal education with a particular emphasis to Integrated Functional Adult Literacy program. As a result, governance structure created and staffed at all levels (Katy, 2007). The focus of Integrated Functional Adult Education program (IFAEP) is to convey knowledge and skills in income generation, environment protection, cultural education, health, civic education, skills in agriculture and enable them to read and write. However, in Ethiopia high level of illiteracy in the adult population is still one of the major barriers to achieving development goals by 2025 . Regarding the status of adult education, the federal Ministry of Education in 2008 pointed out that the program had remained low in terms of accessibility and relevance; it had not been geared towards problem solving and had failed to address the immediate life of the adult community. Education Sector Development Program (ESDP-IV) in the same way revealed that the figure of adult illiteracy has remained high, and the issue has become the main challenge and priority agenda in ESDP V (MoE, 2015).

Despite the greater social, political and economic role, which governments in most third world countries envisage for adult education, the program is at a standstill, severely underresourced and the clarity behind the thought has been lost (Rogers, 1992). The most powerful concept which has been lost by stakeholders is the socio-economic impact of the program. On the other hand, from researchers frequent discussion with stakeholders (facilitators, experts and adult learners) and practical observation on the ground. It was assured that the existing structure has not been well instituted, integrated and functioned as expected. More notably, the task and duty among government, civil society and community is ambiguous (Katy, 2007). However, stand still researcher does not critically investigate the causality and extent of all these problems for policy makers, program designer and implementers as a gap. Furthermore, the contribution of IFAE program to improve the livelihoods of the people is not checked, and research based solution for the challenge encountering the program has not yet recommended for further improvements. Therefore, this research seeks to examine the existing activities, viewpoints and challenges in realizing IFAEP in Eastern Ethiopia.

\subsection{Research Questions}

To investigate the existing practices and challenges of Integrated Functional Adult Literacy issues the researchers intended to answer the following critical research questions.

1. What are the practices of Integrated Functional Adult Education Program in the study areas?

2. To what extent has Integrated Functional Adult Education Program contributed to the improvement of the livelihood of the community?

3. What are the major challenges in the implementation of Integrated Functional Adult Education Program?

\section{LITERATURE REVIEW}

Adult non-formal education is a series of planned and organized educational activities provided outside the formal education system (Tight, 1996). The ultimate rationale of Adult Non-Formal Education (ANFE) is to grant alternative learning opportunities for those who do not have access to formal schooling or specific life skills and knowledge to overcome different obstacles. It is deliberate and organized types of learning as contrasting to incidental learning. The 
meaning of adult education varies at different places and time. However, UNESCO (2006) defined adult education as follows:

Non-formal education has always been part of the solution for marginalized and vulnerable population groups because program are based on an integrated approach that takes in to account all the factors influencing the opportunities and life-chance of different population groups, and the role played by education systems themselves in the process of social inclusion and cohesion.

Regarding its nature, ANFE was less structured, immediate in objectives, goals, management are decentralized, and contents are locally specific, characterized by resource sharing, more task and skill oriented, and flexible in timing (Radcliffe \& Colletta, 1985). Furthermore, andragogically adult education possesses flexible teaching methods, learner-centred rather than teacher-centred, concert and experiential rather than abstract and theoretical. Participation be based on interest and opportunity, teachers should be recruited based on opportunity, tendency and experiences from the grassroots rather than being centrally predetermined. In the last four decades, political and scientific discourse have stressed out on the growing implication of adult education for development. According to IIZ/DVV (2005), adult education plays a fundamental role in promoting social, economic and personal well-being. There is a deep-rooted belief that adult learning has a prospective to create personal, economic and social value (Motschilnig, 2014).

\subsection{Theoretical Framework}

Adult education is a window of opportunity for political, economic and social transformation in Africa. Figure 1 demonstrates the conceptual and theoretical framework of the role of adult education for transformation.

Figure 1 demonstrates that the role of adult education is multisided. Integrated Functional Adult Education can serve as a tool for political, economic and social transformation of a particular society because the focus of it intended to guarantee the active participation of the literate community in the country`s general development Endeavours. The position of adult education for national development is multi-dimensional. It is a foundation for improvement in the areas such as human capital formation, nutrition and prevention of diseases, income generation and productivity, human rights, institution development and democracy. An educated population economically expected to grant a more attractive investment climate. Human capital formation using ANFE is a crucial investment for developing a work force, which is competent in today's global economy (Seya, 2014). However, the function of adult education in development seized by multifaceted relationships existed between the political, economic, cultural and social determinant.

International organization frequently recognized that adult education is a main instrument in reducing poverty across the world (UNESCO-UIL, 2009 as cited in Yilben, 2014). Sabates (2008) also concludes that participating in adult education can help considerably enhancing employment opportunity, reducing poverty, and better living. AE also, improves family health because evidence shows that literate mothers have better family health practices compared to their counter illiterate mothers (Lauglo, 2001). Adult Education has been a concern of states and individuals for decades especially for developing countries like Ethiopia. Literacy is a

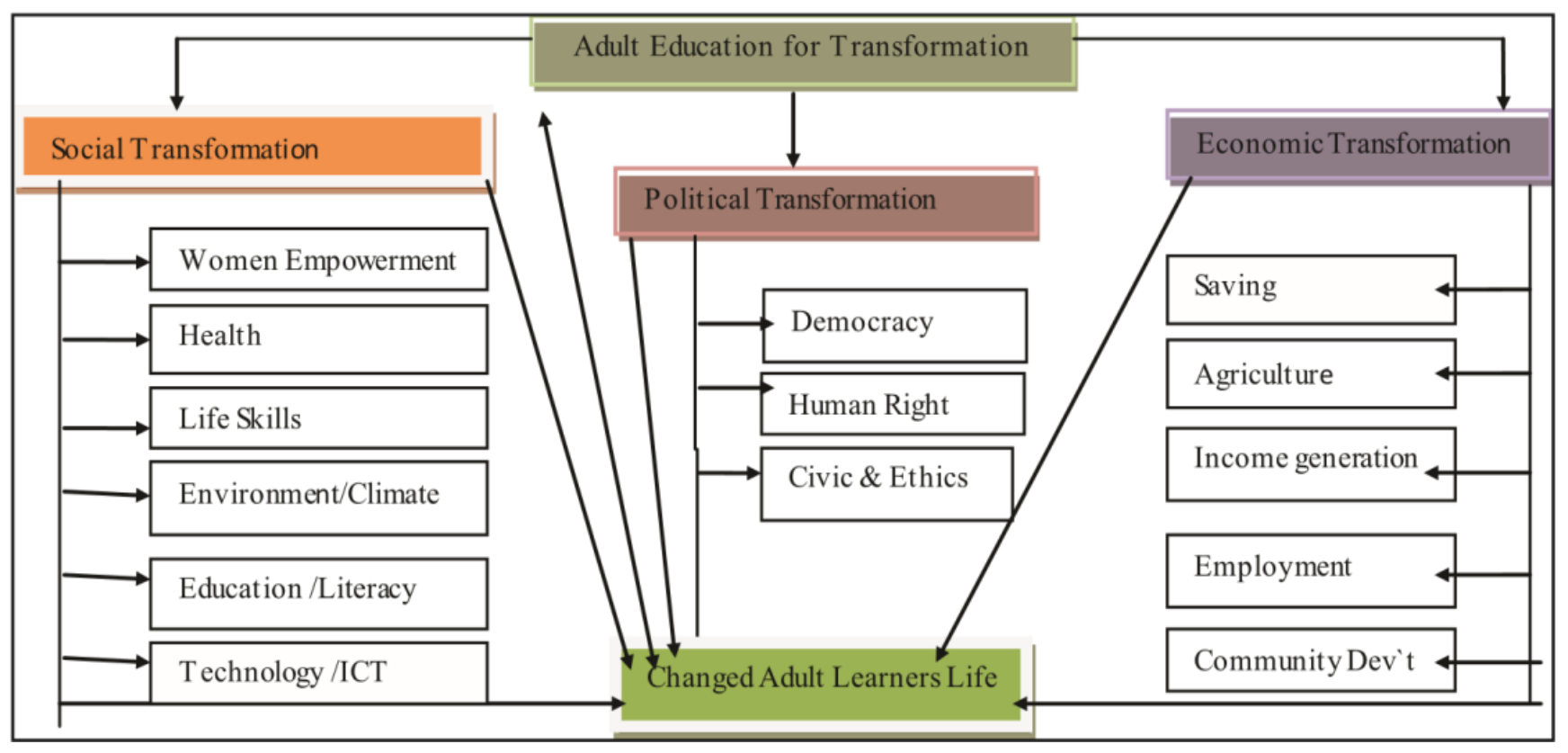

Figure 1: Adult Education for Transformation 
social construct whose definition has evolved historically, often in response to broad economic transformations (OECD, cited in Blackson, 2008). Majority of those who enrol in AE come from the poorer sections of the society. That is to say, AE programs are self-targeting on the very people who should benefit from poverty reduction. Therefore, addressing the poor people on education help to reduce class-based social relations and facilitate to develop the social status of the peoples.

Historically, several authors enlighten as the significant role of education in general and adult non-formal education in particular for democratization of a given countries. American progressive educator Dewey (1966) became an important international reference. He defined the role of education for social change and improvement of democratic life in societies. He also painstakingly described the interdependence between education and democracy. An extra ordinary and influential Brazilian writer P. Freire wrote widely on the role of dialogic, egalitarian and democratic education to social transformation (Freire, 1970). Today, we are witnessing that education is a precondition for political transformation and establishing democratic governance.

Post-basic education makes people more productive and allows them to make informed decision rather easily manipulated by their counter parts (Tilak, 2006). Furthermore, it is argued that education enhances self-esteem among the educated. In the face of globalization where knowledge based economy is appreciated, individual competences and skills are central issues in the labour market (Desjardins, Rubenson \& Milana, 2006). Indeed, jobs need people with certain competences and skills to perform such jobs. $\mathrm{AE}$ is a means to impart such competences and skills. Competent individuals are employable compared to individuals with no or less competences. High rate of unemployment is not just a matter of economic imperfections but also a matter of lack of skills and attitudes among job seekers (Desjardins, Rubenson \& Milana, 2006). Increasing the competency of the individuals within the society through adult education investment considered as a viable strategy. Unless, socio-economic classes and the number of marginalized population will be widen (Desjardins, Rubenson \& Milana, 2006). Furthermore, providing life skills, income generation and saving education make possible the economic security and transformation. Therefore, investment in adult education is investment on improving the productive capacity of the people and the road to transformation.

Arguably, the certainties of the dilemma of the underprivileged or developing country communities require immediate action to augment their position in the global community. The main path to address and adjusts their position in the world depends on community development practices and Consciousness. Furthermore, as a means adult education play pivotal role to improve adult self-reliance, personal autonomy, exercises basic right, increase productivity and labour efficiency (UNESCO, cited in Singh, 1999). In this regard, various countries in the world (both developed and developing) recognized the critical role of adult education to ensure sustainable development.

Ethiopia is familiar with the concept and practices of adult education since the literacy campaign of 1970s. The government used adult education program as a viable instrument to tackle the major problem facing the country such as drought, poverty, unemployment and illiteracy. The government recently designed IFAE in integrated manner (connecting literacy with prevention of disease, improving agricultural productivity, women empowerment, income generation, civic and ethical education, literacy and Numeracy, Environment). The government of Ethiopian envision in their National Growth and Transformation Plans (GTP-II) is building a lower middle- income-country by 2025 (GTP II, 2015). To achieve the objective, the community needs to be literate because building the nation and achieve the development plan with a significant number of illiterate and an ignorant population was unthinkable. Education in general and Integrated Functional Adult Education in particular entrenched the people for actively participation in their political, social and economic affairs (ESDPV). Integrated Functional Adult education recognized as a powerful instrument for women and underprivileged community empowerments that help to reduce ignorance, poverty and bringing skills and awareness to the people.

\subsection{Integrated Functional Adult Education in Ethiopian Context}

Ethiopia recognized education as a key instrument for development in their education and training policy. In the last two and half decades, Ethiopia carried out a massive movement to improve educational access through various education strategies and Education Sector Development Programs (ESDP I, II, III, IV, V) which were derived from the country Education and Training Policy (ETP, 1994). The major objective of the ETP is to produce competent graduate who can actively participate in the economic, political and social development endeavor of the country. However, the problem of quality and relevance needs emphasis. The government of Ethiopia has used adult and non-formal education to assist development in others sectors of their economy. The country recognized that an educated population is a prerequisite to become competitive with in an international financial system. It helps to eradicate illiteracy and enable adult learners to increase problem-solving capacity. Moreover, it enhances the involvement of the public in poverty reduction struggle, empowers to utilize their money in a planned way, has positive impacts on children's school enrolment and gender issue, use technological inputs 
in their livelihoods, and makes adult learners more productive and self-reliant (MoE, 2014/2015).

In an attempt to improve the adult education program, adult education Master Plan was drafted to guide the sector (MoE, 2010). The National Adult Education Strategy put more emphasis to Integrated Functional Adult Literacy Program (IFALP). The two-year IFAE training program provides for those who are between the ages of 15- 60 year old. The program provide by learners first language, literacy, numeracy and other skills development in an integrated manner. It has been designed to make use of inputs from other development workers (agriculture, health, civic and ethics, cooperative, micro and small enterprise institutions etc.). The goal of ANFE is:

To create a learning society by providing adult and nonformal education linked to lifelong learning opportunities that meets the diverse learning needs of all and contributes to personal, societal and economic development (MoE, 2010).

The key policy objective is to increase participation in ANFE programmes. Activities focus on creating and sustaining a literate environment and strengthened institutional capacity through the development of a more coordinated structure for adult education provision in the communities. Training programmes for facilitators and adult education tutors include andragogy as a core component. The development of relevant and quality materials that can be used to teach learners and apply literacy in real life situations through the IFAE course will be part and parcel of the program. Regions should consider the languages and needs of adults' learner in developing appropriate curricula which will serve as frameworks for IFAE materials development at the districtlevel. Adult literacy curricula and implementation manuals should be relevant, particularly to address women empowerment. IFAE graduates will be provided with opportunities and allowed to transfer to formal education and TVET, or to pursue post-literacy courses.

In ESDP V implementation period, the government of Ethiopia has planned to emphasis in mobilizing the necessary resources and strengthens necessary partnership for the successful implementation of Adult education program in the country. The theme is shifted from general adult education program to integrated functional adult education program to ensure the active participation of the community in the social, political and economic sector of the nation. The number of learners, facilitators and centres has been growing (Table 1).

Table 1 below depicts that regions with better adult education enrolment are Amhara, Oromia and SNNP respectively. However, adult education learner in Gambella region is very small compared to other regions. There is high gender disparity in adult education participation at national level. This shows that the shares of illiterate adult females are more than male population in the country.

\section{METHODS}

\section{Research Design}

The researchers used mixed research design. The main methodological concern of the research was descriptive explanation of the responses for the given questionnaires, interview, and focus group discussion and document review with regard to the theoretical and practical framework of Integrated Functional Adult Education. These instruments help to capture viable information and analyze with triangulation (Merriam, 1988, Best and Kahn, 2005, Victor, 2006). Primary data obtained from facilitators, adult learners, and adult education experts/focal person from eastern Ethiopia (Harari, Dire Dawa, and east Hararghe). In addition, as the secondary sources, the researchers used different written materials, national and regional adult education report, policy guidelines, strategies and directive documents, training manuals, and learner portfolios.

\section{Sampling Techniques}

The sample-training centres were selected using simple random sampling techniques. A stratified sampling technique was employed to select 153 sample training-facilitators. The researcher also used expert sampling techniques to select 6 education expertises. This sampling techniques help to access individuals who have distinguished experiences in the area (Scott \& Morrison, 2006 \&Kultar, 2007). Researchers frequently argue that using multiple methods of data collection instrument because the weakness of one tool can improve by other tools (Patton, 2002). Besides, it helps to triangulate the finding during data analysis. Based on this idea, the researchers collected data from 302 learners, 153 facilitators and 6 adult education experts who were accessed through questionnaires and interview guides.

Procedurally the questionnaire was first prepared in English and converted to local language, which were Amharic and Afan Oromo to avoid communication barriers. More importantly, the reliability of the questionnaires was checked (aggregated $\alpha=0.95$ ). The researchers consulted the regional and district education officials to get permission for data collection. The questionnaire were distributed to learners and collected with the direct support of centre facilitators because the learners unable to read and understand the questionnaires. Selected facilitators filled the questionnaire at the same time. The researcher interviewed experts and conducted FGD with selected facilitators at Dire Dawa and Harar.

The collected data was coded and analyzed using SPSS-16. Quantitative data were analyzed using percentage, frequency and mean. Qualitative data were analyzed using narrative and thematic description. 
Table 1. Adult (15-60) Participants in IFAE program by region and gender (2014/15)

\begin{tabular}{|c|c|c|c|c|c|c|c|c|}
\hline \multirow[t]{2}{*}{ No } & \multirow[t]{2}{*}{ Regions } & \multicolumn{3}{|c|}{ Adult enrolment (15-60) } & \multicolumn{3}{|c|}{$\begin{array}{c}\text { Number of facilitators (health, } \\
\text { agriculture, cooperative, } \\
\text { ABE, teacher, other) }\end{array}$} & \multirow[t]{2}{*}{$\begin{array}{l}\text { Learning centres (health, } \\
\text { agriculture, } \mathrm{ABE}, \\
\text { cooperative, school, other) }\end{array}$} \\
\hline & & $\mathbf{M}$ & $\mathbf{F}$ & $\mathbf{T}$ & $\mathbf{M}$ & $\mathbf{F}$ & $\mathbf{T}$ & \\
\hline 1. & Tigray & 234672 & 270085 & 504757 & 2048 & 2453 & 4501 & 1504 \\
\hline 2. & Afar & 17976 & 13290 & 31266 & 75 & 398 & 473 & 281 \\
\hline 3. & Amhara & 1619239 & 983657 & 2602896 & 35762 & 49880 & 85642 & 19115 \\
\hline 4. & Oromiya & 920262 & 654562 & 1574824 & 32451 & 49829 & 82280 & 16918 \\
\hline 5. & Somali & 4923 & 7288 & 12211 & 13 & 179 & 192 & 31 \\
\hline 6. & Benishangul & 32283 & 31844 & 64127 & 1812 & 3152 & 4964 & 437 \\
\hline 7. & SNNP & 572611 & 569336 & 1141947 & 4311 & 13507 & 17818 & 12414 \\
\hline 8. & Gambella & 270 & 627 & 897 & 24 & 59 & 83 & 29 \\
\hline 9. & Harari & 8395 & 4211 & 12606 & 140 & 402 & 542 & 200 \\
\hline 10. & Addis Ababa & 8828 & 22453 & 31281 & 610 & 341 & 951 & 433 \\
\hline \multirow[t]{2}{*}{11.} & Dire Dawa & 8145 & 5452 & 13597 & 57 & 180 & 237 & 157 \\
\hline & Total & 3427604 & 2562805 & 5990409 & 77303 & 120380 & 197683 & 51519 \\
\hline
\end{tabular}

Source: Educational statistics annual Abstract (2014/15)

\section{RESULTS AND DISCUSSION}

As it can be seen below in Table 2, majority of facilitators $112(73.2 \%)$ were male and the remaining $36(23.5 \%)$ were females. Likewise, majority of learners are male which constitute 163 (54.0\%) and the remaining 113 (37.4\%) were woman participants in Integrated Functional Adult Literacy Program in eastern Ethiopia. However, the numbers of women illiteracy are higher than man in the country (MoE, 2015). Likewise, the findings of Dabali (2011) substantiated that female participation was very low in the process of IFAEP implementation. Therefore, women responsive education program and strategies need to be put in place to empower women and make them beneficiary from socio-political and economic practices.

Regarding the age of respondents, as it can be seen below in Table 2, 59 (38.6\%) of facilitators $\geq 31$ years, the remaining $43(28.1 \%)$ between 26-30 years, 41(26.8\%) between $21-25$ years and $8(5.2 \%)$ were $\leq 20$ years. From this, it can be concluded that most of facilitators are mature enough to plan, implement and evaluate the program. With regard to age, majority $139(46.0 \%)$ of learners age ranged 21-30 years, the rest 89 (29.5\%) age ranged $31-40$ years, $35(11.6 \%)$ were $\leq 20$ years and 20 $(6.6 \%)$ were $\geq 41$ years. From this data, we can understand that most of adult learners were with the center of productive age range 15-60 which were young and energetic. Working with this age group is working on the country development program.

As it can be seen below in Table 3, the data collected from three regions Harari, Dire Dawa and East Hararghe, in which 29 (19.0\%) of facilitators and $66(21.9 \%)$ of learners were from Harari Region, 58 (37.9\%) of facilitators and $128(43.1 \%)$ of learners were from East Hararghe, and the remaining $64(41.8 \%)$ of facilitator and 105 (34.8\%) of learners from Dire Dawa City Administration. With regard to working experiences of facilitators, 33 (21.65\%) of facilitators were bingers with $0-2$ years of work experience, $57(37.3 \%)$ of them had 3-5 years of experience, 24 $(15.7 \%)$ of them had 6-8 years of work experience and the remaining $31(20.3 \%)$ of respondents had more than 9 years of working experience.

Concerning the educational level of facilitators, 18 $(11.8 \%)$ of facilitators were 10th or 12th grade complete, $21(13.7 \%)$ of facilitators had TTI certificate, 59 (38.6\%) of facilitators were diploma holders and the remaining $53(34.6 \%)$ of facilitators had BED/BA/BSc degree in other discipline. During the interview session with education expertise and focal persons, one of the experts pointed out that:

Most of adult education facilitators were formal education teachers and the remaining facilitators were grade 10th and 12th complete who have not sufficiently trained on the concept and practice of adult education. They teach literacy and numeracy rather than basic life skills and problem solving issues. Furthermore, coordination and integration problem, lack of continuous support, shortage of well-trained and promoted facilitators disregards the program.

From this data we can concluded that shortage of welltrained facilitators affect the implementation of IFAL program. 
Table 2.Sex and age of facilitators and learners

\begin{tabular}{|c|c|c|c|c|c|c|c|c|c|c|}
\hline \multirow[b]{2}{*}{ Sex } & \multicolumn{2}{|c|}{ Facilitators } & \multicolumn{2}{|c|}{ Learners } & \multicolumn{4}{|c|}{ Age of facilitators } & \multicolumn{2}{|c|}{ Age of learners } \\
\hline & $\underline{\mathbf{N}}$ & $\%$ & $\mathbf{N}$ & $\%$ & Years & $\mathbf{N}$ & $\%$ & Years & $\mathbf{N}$ & $\%$ \\
\hline Male & 112 & 73.2 & 163 & 54.0 & $\leq 20$ years & 8 & 5.2 & $\leq 20$ years & 35 & 11.6 \\
\hline Female & 36 & 23.5 & 113 & 37.4 & $21-25$ years & 41 & 26.8 & 21-30 years & 139 & 46.0 \\
\hline Missing & 5 & 3.3 & 26 & 8.6 & 26-30 years & 43 & 28.1 & $31-40$ years & 89 & 29.5 \\
\hline \multirow[t]{3}{*}{ Total } & 153 & 100.0 & 302 & 100.0 & $\geq 31$ years & 59 & 38.6 & $\geq 41$ years & 20 & 6.6 \\
\hline & & & & & Missing & 2 & 1.3 & Missing & 19 & 6.3 \\
\hline & & & & & Total & 153 & 100.0 & Total & 302 & 100.0 \\
\hline
\end{tabular}

Table 3. Location of learners work experience and educational level of facilitators

\begin{tabular}{|c|c|c|c|c|c|c|c|c|c|}
\hline \multirow[t]{2}{*}{ Location } & \multicolumn{2}{|c|}{ Facilitators } & Learners & \multirow[t]{2}{*}{ Years } & \multicolumn{2}{|c|}{$\begin{array}{l}\text { Work experience } \\
\text { facilitators }\end{array}$} & \multicolumn{3}{|c|}{$\begin{array}{c}\text { Educational level } \\
\text { facilitators }\end{array}$} \\
\hline & $\mathbf{N}$ & $\%$ & $\mathbf{N}$ & & $\mathbf{N}$ & $\%$ & Level & $\mathbf{N}$ & $\%$ \\
\hline Harari NRs & 29 & 19.0 & 66 & $21.90-2$ years & 33 & 21.6 & $10^{\text {th }} \& 12^{\text {th }}$ Comp. & 18 & 11.8 \\
\hline East Hararge & 58 & 37.9 & 128 & $43.13-5$ years & 57 & 37.3 & TTI-certificate & 21 & 13.7 \\
\hline DD City & 64 & 41.8 & 105 & $34.86-8$ years & 24 & 15.7 & Diploma & 59 & 38.6 \\
\hline Missing & 2 & 1.3 & 1 & $0.3 \geq 9$ years & 31 & 20.3 & $\mathrm{BSc} / \mathrm{BA} / \mathrm{BED}$ & 53 & 34.6 \\
\hline \multirow[t]{2}{*}{ Total } & 153 & 100.0 & 302 & 100.0Missing & 8 & 5.2 & Missing & 2 & 1.3 \\
\hline & & & & Total & 153 & 100.0 & Total & 153 & 100.0 \\
\hline
\end{tabular}

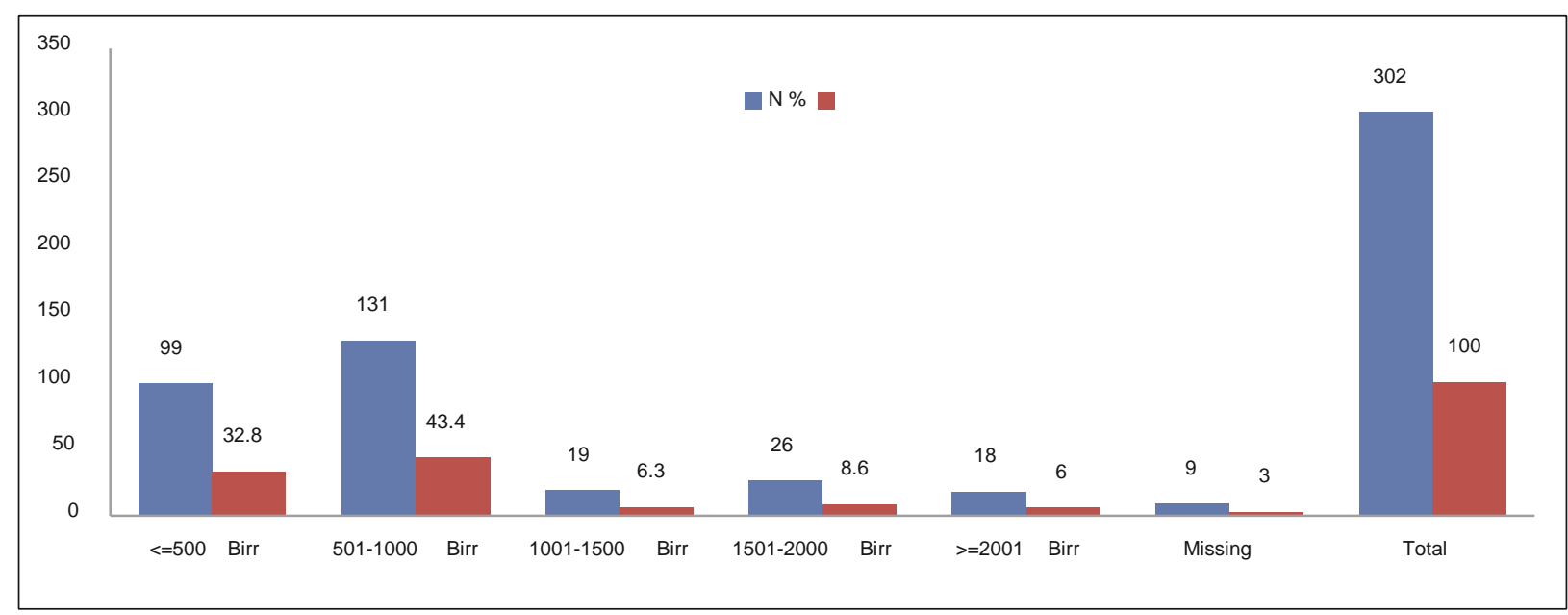

Figure 2: Monthly income of Adult Learners

As it can be observed in Figure 2, 99 (32.8\%) of adult learner monthly income was below 500 Eth birr. Majority $131(43.4 \%)$ of respondents income in a variation between 501-1000 Eth Birr, 19 (6.3\%) of adult learner income 1001-1500 Eth Birr, the rest 26 (8.6\%) had an income between 1501-2000 Eth birr and the remaining 18 (6\%) had an income more than 2001 Eth birr. From this data, we can conclude that most of adult learners were underprivileged and their average income is below the national average. The country`s per capital income in 2016 was $\$ 660$ (Gross National Income, Atlas Method, 2016). Similarly, during the interview and focus group discussion session with facilitators and expertise, they disclosed that most of adult education learners were poor and economically not selfsufficient. To address this people AE program introduced in various centres, and the community awareness were improved, attitudes towards environmental conservation and child and maternal health were considerably increased. However, economically or in cash their incomes were not significantly improved. Therefore, concerned stakeholders need to be re-invigorated adult education program to improve the livelihoods of adult learners. 
Figure 3 revealed that $192(53.6 \%)$ of adult learners live in rural areas, $91(30.1 \%)$ of respondents live in urban areas and the remaining $11(3.6 \%)$ of respondents live in semiurban areas. Ethiopia economy is primarily depending on agriculture, as a result, more than $80 \%$ of the population lives in rural areas. Therefore, focusing on the dilemma of these peoples would be directly or indirectly enable us to alleviate the problem of the country: poverty, drought and migration.

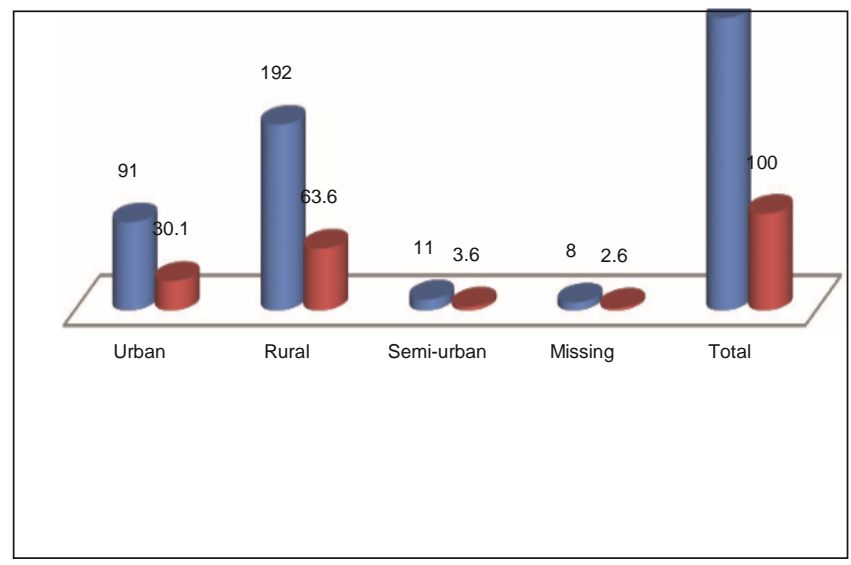

Figure 3: Residence of adult learners

RQ1: What are the practices of Integrated Functional Adult Education Program in the study areas?

As Table 4 depicts, majority 277 (91.7\%) of adult learners are motivated to participate in IFAE program. This is a remarkable opportunity to provide the program an extensive scale because motivation is a force that causes someone to do something or to act or continue to work something. With regard to the level of facilitators motivation, majority 80 $(52.3 \%)$ of facilitators has medium motivation, the remaining $51(33.3 \%)$ has high motivation and $21(13.7 \%)$ has low motivation to facilitate the program. During the focus group discussion session with adult education facilitators, one of them reported that:

Weak motivational mechanisms, low and inconsistent salary of facilitators, lack of professional development program, low infrastructure and support disgruntled the program facilitators and experts.

Therefore, the government of Ethiopia should create adult education facilitator and learner responsive institutional arrangement for the successful implementation of the program.

As it can be seen Table 5, majority 113 (73.9\%) of respondents affirmed that they have appropriate knowledge, skills and attitudes necessary for proper implementation of IFAE program. The remaining $31(20.35 \%)$ of respondents confirmed that they do not have the required Knowledge, skills and attitudes for proper implementation of IFAE program. Regarding the training of facilitators, only 85
(55.6\%) of facilitators were trained to facilitate IFAE program, the remaining $53(34.6 \%)$ of facilitators were not trained for IFAE program. In contrary to the above information, interviewees and educational experts reported that:

Considerable numbers of facilitators are formal education teachers who have short term or no prior training on Integrated Functional Adult Education program.

Recently, higher learning institutions (HLIs) started producing graduates of adult education and community development professionals in undergraduate level and adult education and lifelong learning at postgraduate level. Therefore, the researcher suggested that public service in collaboration with Ministry of Education need to put new structure that absorbs this graduate which may be an input for the successful realization of the program.

As it can be observed in Table 6below, only 41(13.6\%) of adult learners affirmed that facilitators had arranged AE center for learning, and the remaining 259 (85.8\%) of respondents confirmed that facilitators did not arrange the center of AE for learning. Only 46 (15.2\%) of adult learners reported that facilitators asked adult learners to check what the learners know or not after the instruction, the remaining $226(74.8 \%)$ did not ask question after the instruction. Likewise, during focus group discussion, facilitators reported that there is no well-structured assessment mechanism to check whether the desired objectives are achieved or not in adult education program. With regard to usage of additional instructional materials, $146(48.3 \%)$ of adult learners reported that facilitators used additional materials to simplify adult learning and the remaining $142(47.0 \%)$ of adult learners reported that their facilitators did not used additional materials that simplify adult learning. Similarly, during focus group discussion facilitators reported that adult education program is extremely under-resourced both financially and materially. The allocated $8 \%$ share of adult education budget from the national and regional budget was not dispersed for program facilitation. Therefore, realization of the allocated budget and fulfilment of other required resources should be the priority for the program accomplishment.

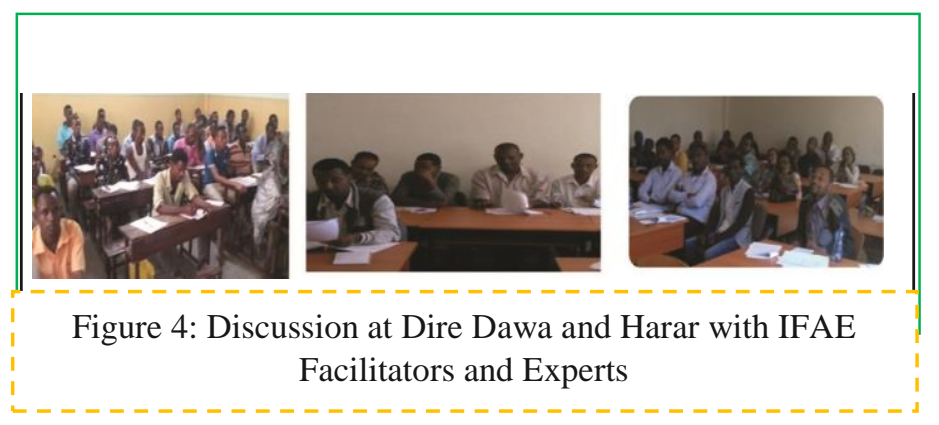


Table 4. Motivation of learners and facilitators

\begin{tabular}{|c|c|c|c|c|c|c|c|}
\hline \multirow[t]{2}{*}{ Item } & \multicolumn{3}{|l|}{ Learners } & \multicolumn{4}{|c|}{ Facilitators } \\
\hline & Response & $\mathbf{N}$ & $\%$ & & Response & $\mathbf{N}$ & $\%$ \\
\hline Are you motivated to & No & 23 & 7.6 & Facilitators level of & Low & 21 & 13.7 \\
\hline \multirow[t]{4}{*}{ Participate on IFAE Program? } & Yes & 277 & 91.7 & motivation to & Medium & 80 & 52.3 \\
\hline & Missing & 2 & 0.7 & facilitate & High & 51 & 33.3 \\
\hline & Total & 302 & 100.0 & IFAE Program & ittatesing & 1 & 0.7 \\
\hline & & & & & Total & 153 & 100.0 \\
\hline
\end{tabular}

Table 5. Facilitators training, knowledge, skills \& attitudes

\begin{tabular}{|c|c|c|c|c|c|c|c|}
\hline \multirow[t]{2}{*}{ Item } & \multicolumn{3}{|c|}{ Facilitators } & \multirow[b]{2}{*}{ Response } & \multirow[b]{2}{*}{$\mathbf{N}$} & \multirow[b]{2}{*}{$\%$} & \\
\hline & Response & $\mathbf{N}$ & $\%$ & & & & \\
\hline Do you have appropriate knowledge, skill \& & No & 31 & 20.3 & Are you trained & No & 53 & 34.6 \\
\hline attitude necessary for proper implementation & Yes & 113 & 73.9 & to facilitate & Yes & 85 & 55.6 \\
\hline of IFAE Program & Missing & 9 & 5.9 & IFAE Program? & Missing & 15 & 9.8 \\
\hline & Total & 153 & 100.0 & & Total & 153 & 100.0 \\
\hline
\end{tabular}

Table 6. Issue related with IFAL Instruction

\begin{tabular}{|c|c|c|c|c|c|c|c|c|}
\hline \multirow[t]{2}{*}{ Items } & \multicolumn{2}{|c|}{ Yes } & \multicolumn{2}{|c|}{ No } & \multicolumn{3}{|c|}{ Missed } & Total \\
\hline & $\mathbf{N}$ & $\%$ & $\mathbf{N}$ & $\%$ & $\mathbf{N}$ & $\%$ & $\mathbf{N}$ & $\%$ \\
\hline Do facilitators arrange the center for learning? & 41 & 13.6 & 259 & 85.8 & 2 & 0.7 & 302 & 100.0 \\
\hline $\begin{array}{l}\text { Do facilitators ask learner on what they know and not after the } \\
\text { instruction? }\end{array}$ & 46 & 15.2 & 226 & 74.8 & 30 & 9.9 & 302 & 100.0 \\
\hline $\begin{array}{l}\text { Do facilitators use additional materials to simplify learners } \\
\text { learning? }\end{array}$ & 146 & 48.3 & 142 & 47.0 & 14 & 4.6 & 302 & 100.0 \\
\hline
\end{tabular}

RQ2: To what extent has integrated Functional Adult Education Program contributed to the improvement of the livelihood of the community.

As it can be seen in Table 7, most of the respondents (adult learner and facilitators) confirmed that Integrated Functional Adult Education played pivotal role in socioeconomic changes and improved adult learners participation in community affairs and their standards of living, the combined mean scores of both respondents were 3.62 and 3.66 respectively However, the role of IFAE to increase Adult learners use of agricultural technology and enhance agricultural productivity were medium, the mean scores of both respondents were 3.23 and 3.49. Furthermore, both adult learner and facilitator respondents affirmed that Integrated Functional Adult Education promotes active participation of adult learner in election, empowers women to face various responsibilities at home and improved income of the individuals. In relation to this, Okech (2009) underpinned that functional adult literacy contributes to economic empowerment particularly by enabling women to make their goods more effectively and that enable them to plan and participates in income generation and proper decision making. In addition to this, participants of IFAE were equipped with essential literacy and numeracy skills through this program, sickness and mortality rates of children and mothers reduced and then increased their life expectancy, improved their understanding about their rights and responsibilities within the society, improved societal participation on environmental protection practice (natural resource conservation) and improved personal and community hygiene. The combined mean score of all items was high, which was above 3.54. Likewise, during interview and focus group discussion session with IFAL facilitators and experts, most of participants confirmed that adult learners in eastern Ethiopia have achieved significant change in prevention of diseases, improved the saving habits of their peoples and understanding about their right and responsibilities within the community. Furthermore, through IFAE program adult agricultural productivity maximized (particularly common cash crops such as chat sorghum, verities of vegetable fruits and potatoes). 
Table 7. Socio-Economic impact of functional adult literacy/education program

\begin{tabular}{|c|c|c|c|c|c|c|c|}
\hline Items & Resp & $N$ & High & Medium & Low & Mean & $S D$ \\
\hline \multirow[t]{2}{*}{ Improve societal participation in community affaires } & $L$ & 301 & $165(54.6 \%)$ & $103(34.1 \%)$ & $31(10.9 \%)$ & \multirow[t]{2}{*}{3.62} & \multirow[t]{2}{*}{0.943} \\
\hline & $F$ & 153 & $60(39.2)$ & $59(38.6 \%)$ & $34(22.2 \%)$ & & \\
\hline \multirow[t]{2}{*}{ Improve standards of living } & $L$ & 301 & $176(58.3 \%)$ & $87(28.8 \%)$ & $37(12.6 \%)$ & \multirow[t]{2}{*}{3.66} & \multirow[t]{2}{*}{1.012} \\
\hline & $F$ & 151 & $64(41.9 \%)$ & $48(31.4 \%)$ & $39(25.5 \%)$ & & \\
\hline \multirow[t]{2}{*}{ Increase the use of agricultural technological } & $L$ & 301 & $128(42.4 \%)$ & $115(38.1 \%)$ & $58(19.3 \%)$ & \multirow[t]{2}{*}{3.32} & \multirow[t]{2}{*}{1.09} \\
\hline & $F$ & 152 & $65(42.5 \%)$ & $51(33.3 \%)$ & $36(23.5 \%)$ & & \\
\hline \multirow[t]{2}{*}{ Enhance agricultural productivity } & $L$ & 299 & $162(53.7 \%)$ & $84(27.8 \%)$ & $53(17.6 \%)$ & \multirow[t]{2}{*}{3.49} & \multirow[t]{2}{*}{1.021} \\
\hline & $F$ & 151 & $73(47.7 \%)$ & $37(24.2 \%)$ & $41(26.8 \%)$ & & \\
\hline \multirow[t]{2}{*}{ Promote active participation in election } & $L$ & 297 & $167(55.3 \%)$ & $100(33.1 \%)$ & $30(10.0 \%)$ & \multirow[t]{2}{*}{3.66} & \multirow[t]{2}{*}{0.966} \\
\hline & $F$ & 153 & $77(50.3 \%)$ & $46(30.1 \%)$ & $30(19.6 \%)$ & & \\
\hline \multirow{2}{*}{$\begin{array}{l}\text { Empower women to face different responsibility at } \\
\text { home }\end{array}$} & $L$ & 300 & $191(63.3 \%)$ & $77(25.5 \%)$ & $32(10.6 \%)$ & \multirow[t]{2}{*}{3.74} & \multirow[t]{2}{*}{0.943} \\
\hline & $F$ & 153 & $85(55.6 \%)$ & $43(28.1 \%)$ & $25(16.4 \%)$ & & \\
\hline \multirow[t]{2}{*}{ Improve income of the individuals } & $L$ & 297 & $165(53.6 \%)$ & $91(30.1 \%)$ & $41(13.5 \%)$ & \multirow[t]{2}{*}{3.54} & \multirow[t]{2}{*}{0.969} \\
\hline & $F$ & 153 & $64(41.8 \%)$ & $61(39.9 \%)$ & $28(18.3 \%)$ & & \\
\hline \multirow{2}{*}{$\begin{array}{l}\text { Prepare learners with essential literacy and } \\
\text { numeracy skills }\end{array}$} & $L$ & 300 & $197(65.3 \%)$ & $77(25.5 \%)$ & $26(8.6 \%)$ & \multirow[t]{2}{*}{3.93} & \multirow[t]{2}{*}{1.003} \\
\hline & $F$ & 152 & $97(43.8 \%)$ & $50(32.7 \%)$ & $35(22.9 \%)$ & & \\
\hline \multirow{2}{*}{$\begin{array}{l}\text { Reducing sickness and mortality rates and by } \\
\text { increasing life expectancy }\end{array}$} & $L$ & 300 & $171(43.8 \%)$ & $81(26.8 \%)$ & $48(15.9 \%)$ & \multirow[t]{2}{*}{3.67} & \multirow[t]{2}{*}{1.171} \\
\hline & $F$ & 151 & $78(51.0 \%)$ & $50(32.7 \%)$ & $23(15.1 \%)$ & & \\
\hline \multirow{2}{*}{$\begin{array}{l}\text { Improve understanding about their rights and } \\
\text { responsibilities within the society }\end{array}$} & $L$ & 302 & $191(63.3 \%)$ & $89(29.5 \%)$ & $22(7.3 \%)$ & \multirow[t]{2}{*}{3.82} & \multirow[t]{2}{*}{0.956} \\
\hline & $F$ & 152 & $78(51.0 \%)$ & $47(30.7 \%)$ & $27(17.7 \%)$ & & \\
\hline \multirow{2}{*}{$\begin{array}{l}\text { Improve environmental protection practice (natural } \\
\text { resource conservation) }\end{array}$} & $L$ & 302 & $194(64.2 \%)$ & $71(23.5 \%)$ & $37(12.2 \%)$ & \multirow[t]{2}{*}{3.74} & \multirow[t]{2}{*}{1.036} \\
\hline & $F$ & 152 & $83(54.3 \%)$ & $46(30.1 \%)$ & $23(15.1 \%)$ & & \\
\hline Improve hygiene (personal and community hygiene) & $L$ & 302 & $199(66.3 \%)$ & $61(20.2 \%)$ & $42(13.9 \%)$ & 3.81 & 1.121 \\
\hline & $F$ & 152 & $77(50.3 \%)$ & $49(32.0 \%)$ & $26(17.0 \%)$ & & \\
\hline
\end{tabular}

NB: Analysis interval of mean score: 1.0--2.5=Low, 2.51-3.5=Medium, 3.51--5.0=High F=Facilitators \& L=Learner

$R Q$ 3: What are the major challenges in the implementation of Integrated Functional Adult Education Program?

To analyze this data the researchers merged very high and high = "high", Low and very low ="low"

As it can be seen in Table 8, lack of trained facilitators and expertise, lack of societal awareness, lack of financial support, lack of continuous supervision, low quality of teaching materials, lack of structures system, lack of interest and motivation of facilitators, low political commitments among political leaders to sustain the IFAE program were the major challenges. The grand combined mean of respondents was 3.23 which indicated the problem for the above listed items were medium. Likewise, during focus group discussion most of participants confirmed that government in Ethiopia has political will but not committed to implement IFAL program. Moreover, there is no consistent discussion and leadership commitment towards mass literacy in the world.
For that reason, we suggested that literacy program required the commitment of the national government in strategic planning, financing, and delivering and working with range of partners. Similarly, local research conducted by Mohammed (2013) concluded that, lack of incentive and adequate training of facilitators, low commitment and motivation of facilitators, lack of adequate budget and facilities affect the implementation of IFAL program in Eastern Hararghe. Furthermore, during the series of discussions with adult education experts and facilitators, it was disclosed that the government made many efforts to build the technical capacity of IFAE staff, developed guidelines, directives, and training materials. However, the impact is not desirable as participants of focus group discussion and interviewees explained it. It was found out that the following major challenges and constraints were 
negatively affecting the existing Integrated Functional Adult Education practices in Ethiopia:

1) Adult education boards do not operate effectively at all levels. This makes implementation, coordination, linkage between program providers more difficult.

2) Absences of trained, reasonably paid, dedicated and committed experts to manage and coordinate the programs were made the expected technical support more complicated.

3) Low and inconsistent budget allocation, poor capacity of facilitators and shortage of infrastructure at the training centres such as electricity, learning materials and other logistics provisions were affecting the implementation of IFAL program.

4) Lack of post-literacy materials has affects the continuation of the program. Such condition may bring a relapse of illiteracy in the country.
5) Low and incompetent facilitators' with inefficient andragogical, monitoring and evaluation skills in most of IFAE centres. This makes the teaching learning process traditional and many of participants could not be assessed effectively.

6) Low and inconsistent salary of facilitators and lack of continuous professional development program that forced the facilitators for high turnover.

7) Lack of prior adequate orientation and training of facilitators on the philosophy and peculiar nature of adult education program.

8) Poor political commitment of leaders and misunderstanding on the program at various level and absence of well-organized and independent managing structure for the program.

Table 8. Major challenges that encounter the practices of IFAE

\begin{tabular}{|c|c|c|c|c|c|c|c|}
\hline Items & Resp't & $\mathbf{N}$ & High & Medium & Low & Mean & SD \\
\hline \multirow{2}{*}{$\begin{array}{l}\text { Lack of trained facilitator and expertise on } \\
\text { andragogy }\end{array}$} & $\mathrm{L}$ & 302 & $112(37.1 \%)$ & $75(24.8 \%)$ & $77(38.1 \%)$ & \multirow[t]{2}{*}{3.22} & \multirow[t]{2}{*}{1.23} \\
\hline & $\mathrm{F}$ & 150 & $66(43.1 \%)$ & $57(37.3 \%)$ & $27(17.6 \%)$ & & \\
\hline \multirow[t]{2}{*}{ Societal awareness problem about the program } & $\mathrm{L}$ & 300 & $103(34.1 \%)$ & $134(44.4 \%)$ & $63(20.9 \%)$ & \multirow[t]{2}{*}{3.30} & \multirow[t]{2}{*}{1.081} \\
\hline & $\mathrm{F}$ & 151 & $74(48.3 \%)$ & $41(26.8 \%)$ & $36(23.6 \%)$ & & \\
\hline \multirow{2}{*}{$\begin{array}{l}\text { Lack of financial support for those who engage } \\
\text { in the program }\end{array}$} & $\mathrm{L}$ & 301 & $138(45.7 \%)$ & $80(26.5 \%)$ & $82(27.1 \%)$ & \multirow[t]{2}{*}{3.37} & \multirow[t]{2}{*}{1.342} \\
\hline & $\mathrm{F}$ & 151 & $70(45.7 \%)$ & $43(28.1 \%)$ & $38(24.8 \%)$ & & \\
\hline \multirow{2}{*}{$\begin{array}{l}\text { Lack of continuous training to facilitators and } \\
\text { experts }\end{array}$} & $\mathrm{L}$ & 301 & $137(45.4 \%)$ & $69(22.8 \%)$ & $95(31.5 \%)$ & \multirow[t]{2}{*}{3.28} & \multirow[t]{2}{*}{1.326} \\
\hline & $\mathrm{F}$ & 149 & $67(43.8 \%)$ & $36(23.5 \%)$ & $46(30.1 \%)$ & & \\
\hline \multirow{2}{*}{$\begin{array}{l}\text { Lack of continuous supervision from woreda } \\
\text { education office }\end{array}$} & $\mathrm{L}$ & 301 & $141(46.7 \%)$ & $70(23.2 \%)$ & $90(29.8 \%)$ & \multirow[t]{2}{*}{3.31} & \multirow[t]{2}{*}{1.638} \\
\hline & $\mathrm{F}$ & 149 & $68(44.5 \%)$ & $32(20.9 \%)$ & $48(31.4 \%)$ & & \\
\hline \multirow{2}{*}{$\begin{array}{l}\text { Low quality of teaching materials and demand } \\
\text { drive guideline }\end{array}$} & $\mathrm{L}$ & 301 & $144(47.6 \%)$ & $64(21.2 \%)$ & $93(30.8 \%)$ & \multirow[t]{2}{*}{3.29} & \multirow[t]{2}{*}{1.282} \\
\hline & $\mathrm{F}$ & 150 & $66(43.1 \%)$ & $40(26.1 \%)$ & $44(28.7 \%)$ & & \\
\hline \multirow{2}{*}{$\begin{array}{l}\text { Lack of structured system with role and } \\
\text { responsibilities to run the program }\end{array}$} & $\mathrm{L}$ & 300 & $152(50.4 \%)$ & $94(31.1 \%)$ & $57(17.9 \%)$ & \multirow[t]{2}{*}{3.33} & \multirow[t]{2}{*}{1.149} \\
\hline & $\mathrm{F}$ & 148 & $57(37.35 \%)$ & $46(30.1 \%)$ & $45(29.4 \%)$ & & \\
\hline \multirow{2}{*}{$\begin{array}{l}\text { Lack of interest to facilitate the program in side } \\
\text { of facilitator }\end{array}$} & $\mathrm{L}$ & 296 & $115(38.0 \%)$ & $71(23.5 \%)$ & $110(36.4 \%)$ & \multirow[t]{2}{*}{3.07} & \multirow[t]{2}{*}{1.163} \\
\hline & $\mathrm{F}$ & 150 & $47(30.7 \%)$ & $55(35.9 \%)$ & $48(31.3 \%)$ & & \\
\hline \multirow[t]{2}{*}{ Timing problem (time of the training) } & $\mathrm{L}$ & 295 & $136(45.0 \%)$ & $7(24.2 \%)$ & $86(28.4 \%)$ & \multirow[t]{2}{*}{3.12} & \multirow[t]{2}{*}{1.145} \\
\hline & $\mathrm{F}$ & 149 & $52(34.0 \%)$ & $47(30.7 \%)$ & $50(32.6 \%)$ & & \\
\hline \multirow{2}{*}{$\begin{array}{l}\text { Lack of motivation to facilitate the program in } \\
\text { side of facilitator }\end{array}$} & $\mathrm{L}$ & 301 & $134(44.3 \%)$ & $76(25.2 \%)$ & $91(30.2 \%)$ & \multirow[t]{2}{*}{3.14} & \multirow[t]{2}{*}{1.198} \\
\hline & $\mathrm{F}$ & 149 & $62(40.6 \%)$ & $43(28.1 \%)$ & $46(30.0 \%)$ & & \\
\hline \multirow{2}{*}{$\begin{array}{l}\text { Lack of political commitment among leaders to } \\
\text { sustain the literacy campaign }\end{array}$} & $\mathrm{L}$ & 301 & $134(44.3 \%)$ & $55(18.2 \%)$ & $112(37.1 \%)$ & \multirow[t]{2}{*}{3.17} & \multirow[t]{2}{*}{1.278} \\
\hline & $\mathrm{F}$ & 150 & $47(30.7 \%)$ & $43(28.1 \%)$ & $60(39.2 \%)$ & & \\
\hline Grand mean & & & & & & 3.23 & \\
\hline
\end{tabular}

NB: Analysis interval of mean score: 1.0--2.5=Low, 2.51-3.5=Medium, 3.51--5.0=High F=Facilitators \& L=Learners

their participation in environmental conservation and protection, health and habit of saving. However, lack of

skilled work force, low and inconsistent budgeting, poor coordination, communication and networking among various concerned stakeholders, weak institutional rural areas of eastern parts of Ethiopia. Their understanding about harmful traditional practices improved, increased

\section{CONCLUSIONS AND RECOMMENDATIONS}

The practice of integrated functional adult education has been benefited considerable number of adults live in the 
arrangement and structure, low awareness of community and poor infrastructure and logistics affect the implementation of IFAL.

Based on the preceding findings and conclusions the following recommendations were forwarded:

a) This research finding revealed that lack of budget, lack or non-existence of independent strong adult education structure; dysfunctional adult education board, poor coordination and unavailability of skilled human resources at various levels negatively affect the implementation of IFAL program. Therefore, the government of Ethiopia and regional states ought to be committed to create independent adult education structure which will comprise administrator, information management, training and consultancy professional, adult education training management and supervision experts, Educational Management Information System (EMIS) curriculum development, and training experts with well trained and remunerated professionals at all levels.

b) Integrated functional adult education plays a pivotal role in attaining sustainable social, economic and political development. However, stakeholders have not played their role on program implementation. Hence, it is recommended that there should be strong partnership and cooperation among major actors in IFAEP implementation such as signatory ministries, financial institutions, public organizations, NGOs and private sectors at all levels.

c) This study revealed that considerable number of facilitators and experts were not well trained on adult education theoretical and practical matters that help us to appropriately manage, deliver and assess IFAL program. Hence, it is recommended that governments should develop appropriate and demand driven instructional materials and mode of delivery, afford infrastructures, improve training and employment condition and professionalization of adult educators, design measurement, monitoring and evaluation mechanism at all stages; input, process and outcome to ensure quality IFALP in the country.

\section{REFERENCES}

Best, J. \& Khan, J. (2005).Research in Education. New Delhi: Prentice-Hall.

Blackson (2008).Contemporary Adult Education Policies and Practices in Tanzania. Thousand Oaks (California): Sage.

MoE (2010).Education Sector Development Program IV. 2010/11 (2010/11-2014/15).Program Action Plan/PAP. Ethiopia.

MoE (2008).National Report on the Development and State of Art of Adult Learning and Education. A.A unpublished. Ethiopia.

Bhola, H. (1984) Functional Literacy or Workplace Literacy and Technical and Vocational Education: Interfaces and Policy. UNESCO, Paris.

Coombs, P H \& Ahmed, M. (1985).Attacking Rural Poverty: How NFE Can Help. The Johns Hopkins University Press Baltimore and London
Dabali, H. (2011). Factors Affecting the Participation of Women in Functional Adult Literacy Program: The case of Nejo Worda of West Wollega Zone of Oromia Region (Unpublished MA thesis). AAU.

David, S. \& Marlene, M. (2006).Key Ideas in Educational Research: Continuum International Publishing Group Antony: Wiltshire. Great Britain.

Dewey, J. (1966). Democracy and Education. New York: Library of Alexandria.

Education for All (2015).National Review Report. Ethiopia: UNESCO.

Freire, P. (1970). Pedagogy of the Oppressed. The Continuum International Publishing Group Ltd.: London.

Gash, R. \& Zachariah, M. (1987). Education and the Press of Change. New Delhi: New Delhi Publication.

IIZ/DVV- Poverty Reduction and Capacity Building through Livelihood Skill Training at CSTCs and VTCs: The EXPRO in Ethiopia, Internal Paper No. 33, IIZ/DVV, June 2005.

Jossey-Bass. (2007). The Profession and Practice of Adult Education: An Introduction. San Francisco: John Wiley \& Sons, Inc.

Katy. (2007). Education for All Global Monitoring Report: Non-Formal and Basic Education Ethiopia Country Profile: UNESCO.

Kultar, S. (2007). Quantitative Social Research Methods. Thousand Oaks (California): Sage Publication.

Lauglo, J. (2001). Engaging with Adults: The case for Increased Support to Adult Basic Education in SubSaharan Africa. Washington: the World Bank.

Merriam, S. B. (1988). Qualitative Research and Case Study Applications in Education. San Francisco. CA: John Wiley \& Sons, Inc.

Patton, M. Q. (2002). Qualitative Research and Evaluation Methods (3rded.). Thousand Oaks (California): Sage Publication.

MoE (2005).The Federal Democratic Republic of Ethiopia, (ESDP-III) 2005/2006-2010/2011, Program Action Plan, Ministry of Education, Addis Ababa.

MoE (2015).Education Sector Development Programme $V$ (ESDP V) Programme Action Plan 2005/16 2019/20 G.C, Addis Ababa. Ethiopia.

MoE (2014/15).Educational Statistics Annual Abstract. Educational Management Information System (EMIS) and ICT Directorate Addis Ababa, Ethiopia. Retrieved from www.moe.gov.et

Mohammed, S. (2013). Implementation of Integrated Functional Adult Education Program: the case of Obora Sub-Zone of Eastern Hararghe: MA thesis. Haramaya University. Ethiopia.

Motschilnig, R. (2014). Wider Benefits of Adult Education- An Inventory of Existing Studies and Research.http://www.dvvinternation.de/index.php?article-id=1321\&clang=1 . 
Nafukho, W. (2011).Management of Adult Education Organization in Africa. UNESCO: Institute for Education.

Okech, A. (2009). Functional Adult Literacy and Poverty Reduction. In Sandhaas B. (Ed.).Cross National Encounters in Adult Education (pp. 15-22). Addis Ababa (Ethiopia): DVV International.

Radcliffe, D. J., \&Colletta, N. J. (1985). Non-formal Education.In T. Husen \& T. N. Postlethwaite (Eds.).The International Encyclopaedia of Education: Research and Studies. Oxford: Pergamon Press.

Rogers, A. (1992). Adults Learning for Development. London: Cassell.

Rogers, A. (1996). Teaching Adults. Buckingham: Open University Press Rowe Ltd.

Sabo, I. \& Mpofu, S. (2006). The Social Context of Adult Learning in Africa .UNESCO .Institute for Education.

Singh, M. (1999).Investing in Human Development- the Economics and Financing of Adult Learning. Paris: UNESCO.

Seya, P. T. (2014). Adult Education and African Development in the Context of Globalization. Addis Ababa (Ethiopia): DVV International.

Tekalign, M. (2010).The Practices in the Management of Community Skill Training Centers in selected Wordas of Ilubabor Zone of Oromia regional: Addis Ababa, (Unpublished MA thesis), Ethiopia.

Tight, M. (1996).Key Concepts in Adult Education and Training. London: Rutledge.

Tilak, J. (2006). The Role of Post Basic Education in Alleviation of Poverty and Development. Edinburgh: Centre of African Studies, University of Edinburgh.

UNESCO (1997b).Final Report on CONFINTEA V. Hamburg: UNESCO, Institute of Education.

UNESCO (1976).The Experimental World Literacy Program: Paris: UNESCO.

Victor, J. (2006). The Sage Dictionary of Social Research Methods. Thousand Oaks (California): Sage Publication.

Yilben, J. J. \& Maikano, P. N. (2014).The Role of Adult Education in National Development. International Letters of Social and Humanistic Sciences, 32, 3542. 